Revista Universo Contábil, ISSN 1809-3337

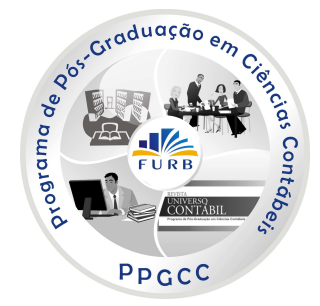

\title{
ANÁLISE DAS PRÁTICAS DE DIVULGAÇÃO DO AJUSTE AO VALOR PRESENTE PELAS COMPANHIAS LISTADAS NA BM\&FBOVESPA ${ }^{1}$
}

\section{ANALYSIS OF THE DISCLOSURE PRACTICES ON ADJUSTED PRESENT VALUE BY COMPANIES LISTED IN BM\&FBOVESPA}

\author{
ANÁLISIS DE LAS PRÁCTICAS DE DIVULGACIÓN DEL AJUSTE DEL VALOR \\ PRESENTE POR PARTE DE LAS EMPRESAS BRASILEÑAS COTIZADAS EN LA \\ BM\&FBOVESPA
}

\author{
Vera Maria Rodrigues Ponte \\ Doutora em Controladoria e Contabilidade pela FEA/USP \\ Professora da Universidade Federal do Ceará - UFC \\ Endereço: Rua Dr. Tomas Pompeu 111/1200, Meireles \\ CEP: 60160-080 - Fortaleza/CE - Brasil \\ E-mail: vponte@fortalnet.com.br \\ Telefone: (85) 3248- 6669 \\ Marcelle Colares Oliveira \\ Doutora em Controladoria e Contabilidade pela FEA/USP \\ Professora da Universidade de Fortaleza - UNIFOR \\ Endereço: Rua Barão de Aracati, 2715/1301, Joaquim Távora \\ CEP: 60115-082 - Fortaleza/CE - Brasil \\ E-mail: marcellecolares@unifor.br \\ Telefone: (85) 3246-5577 \\ Danival Sousa Cavalcante \\ Mestre em Administração e Controladoria pela UFC \\ Endereço: Rua Moreira Gomes, 448 \\ CEP: 60410-720 - Fortaleza/CE - Brasil \\ E-mail: danivalsc@hotmail.com \\ Telefone: (85) 8605-9148 \\ Márcia Martins Mendes De Luca \\ Doutora em Controladoria e Contabilidade pela FEA/USP \\ Professora da Universidade Federal do Ceará - UFC \\ Endereço: Rua Cel. Jucá, 1000/150, Aldeota \\ CEP: 60170-320 - Fortaleza/CE - Brasil \\ E-mail: marciadeluca@ufc.br \\ Telefone: (85) 3261-1705
}

\footnotetext{
1 Artigo recebido em 10.12.2010. Revisado por pares em 06.04.2011. Reformulado em 23.05.2011. Recomendado para publicação em 25.05.2011 por Ilse Maria Beuren (Editora). Publicado em 31.01.2012. Organização responsável pelo periódico: FURB.
} 


\section{RESUMO}

Estudos acadêmicos, como o realizado por Botosan, em 1997, e Forker, em 1992, constataram que empresas com melhor estrutura de governança corporativa apresentaram nível mais elevado de disclosure. Esta pesquisa tem como objetivo investigar o grau de observância das práticas de divulgação relativas ao Ajuste a Valor Presente (AVP), quando da adoção inicial da Lei ${ }^{\circ}$. 11.638/07 e da Lei $n^{\circ}$. 11.941/09, examinando se existiu uma maior observância pelas empresas dos níveis diferenciados de governança corporativa (NDGC) da BM\&FBovespa. Caracteriza-se como um estudo descritivo, tendo sido levantadas as práticas de divulgação das companhias abertas, por meio do exame das demonstrações contábeis, do exercício findo em 2008, de uma amostra de 334 empresas. Aplicou-se o teste de diferenças entre médias de Mann-Whitney para verificar se nas empresas dos NDGC há maior observância das orientações de divulgação, quando comparadas com as do mercado tradicional. Verificou-se baixo grau de observância das práticas de divulgação relativas ao AVP e não se observou maior atendimento às orientações de divulgação por parte das empresas dos NDGC. Os resultados reforçam os achados de pesquisa publicada por Santos e Calixto (2009), demonstrando que a transparência foi negligenciada nas demonstrações contábeis de 2008, até mesmo pelas empresas do Novo Mercado da BM\&FBovespa.

Palavras-chave: Ajuste a valor presente. Práticas de divulgação. Empresas brasileiras.

\section{ABSTRACT}

Academic studies, as the ones performed by Botosani, in 1997, and Forker in 1992, found that companies with better corporate governance structure showed higher level of disclosure. The goal of this research is to investigate the degree of compliance of the disclosure practices regarding the Adjusted Present Value (APV), around the adoption of Law no. 11638/07 and Law no. 11941/09, examining whether there was better compliance by companies of different levels of corporate governance (DLCG) of BM \& F Bovespa. This is characterized as a descriptive study, in which the disclosure practices of companies were analyzed through the examination of financial statements of the year 2008, having 334 companies as sample. The test Mann-Whitney of differences between means was applied to verify if companies with the DLCG show more compliance to the disclosure guidelines when compared to the traditional market. There was a low degree of compliance to disclosure practices related to APV and there was no more compliance to the disclosure guidelines by companies with DLCG. The results reinforce the findings of research published by Santos and Calixto (2009), demonstrating that transparency has been neglected in the financial statements of 2008, even by the companies of the New Market of BM \& F Bovespa.

Keywords: Adjusted present value. Practices of disclosure. Brazilian companies.

\section{RESUMEN}

Estudios académicos, como los realizados por Botosani, en 1997, y Forker en 1992, encontraron que las empresas con mejor nivel de gobierno corporativo mostraron un nivel de disclosure más alto. Esta investigación tiene como objetivo investigar el grado de cumplimiento de las prácticas de divulgación en relación con el ajuste del valor presente (AVP), desde la aprobación de las Leyes 11.638/07 y 11941/09, examinando si hubo un mayor cumplimiento por parte de las empresas de los diferentes niveles de gobierno corporativo (NDGC) de la Bolsa de Valores de São Paulo (BM\&FBovespa). Se caracteriza por ser un estudio descriptivo, cuyas prácticas de divulgación de las sociedades cotizadas fueron investigadas para examinar los informes financieros del año terminado en 2008. Se 
analizó una muestra de 334 empresas. Fue aplicado el teste de diferencias de medias de Mann-Whitney para ver si las empresas del NDGC tienen mejores directrices de divulgación en comparación con las empresas del mercado tradicional. Hubo bajo nivel de cumplimiento de las prácticas de divulgación de la AVP y no se observó mayor cumplimiento de directrices por las empresas de NDGC. Los resultados refuerzan la investigación publicada por Santos y Calixto (2009), lo que demuestra que la transparencia se ha sido descuidado en los informes financieros para el año 2008, incluso las empresas del 'Novo Mercado' de la BM\&FBovespa.

Palavras clave: Ajuste del valor presente. Las prácticas de divulgación. Las empresas brasileñas.

\section{INTRODUÇÃO}

A Lei $\mathrm{n}^{\circ}$. 11.638, de 28/12/2007, introduziu significativas mudanças na legislação societária brasileira, objetivando, principalmente, convergir as práticas contábeis brasileiras com as normas internacionais de contabilidade (International Financial Reporting Standards - IFRS), emitidas pelo International Accounting Standards Board (IASB), órgão responsável pela elaboração dos padrões contábeis internacionais.

Referida lei revogou e/ou alterou diversos dispositivos da Lei $n^{\circ}$. 6.404/76 (Lei das Sociedades Anônimas) e estendeu às sociedades de grande porte as disposições relativas à elaboração e divulgação das demonstrações financeiras (BRASIL, 2007). A Medida Provisória (MP) $n^{\circ}$. 449, de 03/12/2008, convertida na Lei $n^{\circ}$. 11.941, de 27/05/2009, introduziu novas alterações na legislação societária brasileira, consolidando o que muitos especialistas consideram o momento de maiores alterações nas práticas contábeis dos últimos 30 anos (GIROTTO, 2009).

A maioria dessas alterações visa ao processo de convergência das normas contábeis, com a finalidade de harmonizar a informação contábil, tornando-a uma linguagem única e inteligível, o que, consequentemente, tende a reduzir a assimetria informacional e os conflitos de agência entre usuários, bem como a melhorar a transparência, a qualidade e a comparabilidade das informações contábeis.

Já na vigência da nova legislação societária, o Comitê de Pronunciamentos Contábeis (CPC), órgão responsável pelo estudo, preparo e emissão de pronunciamentos técnicos de contabilidade no Brasil, editou vários pronunciamentos no sentido de possibilitar a emissão de normas pelas entidades reguladoras e orientar o seu atendimento. Os pronunciamentos do CPC não têm cunho compulsório, porém, quando aprovados por órgãos reguladores de mercados ou órgãos fiscalizadores, como por exemplo, Comissão de Valores Mobiliários (CVM), Conselho Federal de Contabilidade (CFC), Superintendência de Seguros Privados (SUSEP), Agência Nacional de Energia Elétrica (ANEEL), Agência Nacional de Saúde (ANS) e outros, o transformam em resoluções, deliberações, instruções normativas, circulares, passando a possuir caráter normativo, devendo ser obrigatoriamente seguidos pelas companhias reguladas.

Algumas mudanças introduzidas pela nova legislação societária impactaram diretamente o patrimônio líquido e o resultado das empresas, ao aproximarem os números contábeis da realidade econômica. Dentre essas alterações, tornou-se obrigatória a realização do Ajuste a Valor Presente (AVP) de ativos e passivos circulantes e não-circulantes, quando existir efeito relevante. As Leis $\mathrm{n}^{\circ}$. 11.638/07 e $\mathrm{n}^{\circ}$. 11.941/09 introduziram esse conceito. E, para orientar as práticas contábeis dessa exigência normativa, em 2008 o CPC emitiu o Pronunciamento Técnico ${ }^{\circ} .12$ (CPC 12) - Ajuste a Valor Presente (AVP).

O CPC 12 tem como principal objetivo estabelecer os requisitos a serem observados quando do AVP dos elementos do Ativo e do Passivo, ao ensejo da elaboração de 
demonstrações contábeis, dirimindo as questões controversas advindas de tal procedimento (CPC, 2008a). O CPC 12 define um conjunto de práticas de divulgação dos procedimentos realizados quando do AVP, a ser observado pelas companhias.

Também em 2008, foi aprovado o Pronunciamento Técnico n 13 (CPC 13) - Adoção Inicial da Lei $\mathrm{n}^{\circ}$. 11.638/07 e da MP $\mathrm{n}^{\circ}$. 449/08, com o objetivo de assegurar que as primeiras demonstrações contábeis elaboradas de acordo com as novas práticas contábeis contenham informações capazes de: a) proporcionar um adequado ponto de partida para a contabilidade, de acordo com as novas práticas contábeis; b) garantir transparência para os usuários; e c) ser geradas a um custo que não supere o valor dos benefícios para os usuários (CPC, 2008b).

No tocante ao Ajuste a Valor Presente, o CPC 13 ratificou as orientações contidas no CPC 12 e definiu que, na data da transição, o AVP deve ser realizado contra a rubrica Lucros ou Prejuízos Acumulados, admitindo-se para todos os saldos em aberto o cálculo de forma individual ou em cálculo global, se todos tiverem características uniformes.

Por meio das Deliberações $n^{\circ}$. 564/08 e $\mathrm{n}^{\circ}$. 565/08, a CVM aprovou as orientações contidas nos CPCs 12 e 13, respectivamente, tornando obrigatória a sua observância pelas companhias abertas, inclusive quanto às disposições específicas referentes às práticas de divulgação relacionadas ao AVP realizado sobre os itens patrimoniais (CVM, 2008a, 2008b). Estudo de Santos e Calixto (2009) demonstram que o AVP causou impactos relevantes sobre as demonstrações contábeis das companhias no exercício de 2008.

Estudos, como os de Botosan (1997) e Forker (1992), indicam haver uma correlação entre o nível de disclosure e as características de governança, apontando que as empresas com melhor estrutura de governança apresentariam nível mais elevado de disclosure.

Nesse contexto, e dado que o AVP causou impactos sobre as demonstrações contábeis das companhias no exercício de 2008 (SANTOS; CALIXTO, 2009), resolveu-se investigar se as empresas vêm observando as novas exigências da legislação societária, notadamente no tocante à divulgação de informações referentes a essa prática. Assim, este estudo procura responder os seguintes questionamentos: Qual o grau de observância das orientações do CPC 12 pelas companhias listadas na BM\&FBovespa no que tange às práticas de divulgação acerca do Ajuste a Valor Presente (AVP)? Nas empresas listadas nos níveis diferenciados de governança corporativa (NDGC) da BM\&FBovespa é maior a observância das orientações de divulgação do CPC 12, quando comparadas com as do segmento tradicional?

A pesquisa foi desenvolvida com o intuito de investigar o grau de observância das práticas de divulgação definidas no CPC 12, relativas ao AVP, quando da adoção inicial da Lei $n^{\circ}$. 11.638/07 e da Lei $n^{\circ}$. 11.941/09, examinando se houve maior observância pelas empresas do NDGC.

O pressuposto é de que as empresas com melhores práticas de governança corporativa têm maior compromisso com a transparência e a prestação de informações fidedignas. Assim, dado que, segundo Santos e Calixto (2009), existiu grande diversidade no grau de aderência das empresas às normas de adoção da Lei $\mathrm{n}^{\circ}$. 11.638/07, tem-se como hipótese, que nem todas as companhias observaram as orientações de divulgação do CPC 12 e nas empresas listadas nos níveis diferenciados de governança corporativa da BM\&FBovespa, registrou-se uma maior proporção no tocante à observância das orientações de divulgação.

A relevância da pesquisa está na escassez de pesquisas acerca da evidenciação de informações sobre o Ajuste a Valor Presente à luz do CPC 12, devido à relativa complexidade do assunto e, também, por ser recente a citada norma. Outro ponto destacado refere-se à contribuição por uma estrutura ideal de disclosure, já que possibilita observar, pelo menos em relação ao ponto estudado, o grau de evidenciação das empresas brasileiras.

$\mathrm{O}$ artigo foi estruturado em seis tópicos, incluindo esta introdução. No segundo, evidencia-se o processo de convergência das normas contábeis. Em seguida, aborda-se sobre o Ajuste a Valor Presente em conformidade com as Leis $n^{\circ} .11 .638 / 07$ e $n^{\circ} .11 .941 / 09$ e as 
orientações do Comitê de Pronunciamentos Contábeis e da Comissão de Valores Mobiliários. Na quarta seção, analisam-se os aspectos metodológicos utilizados na pesquisa. Na sequência, apresentam-se os resultados da pesquisa, vindo em seguida as conclusões do estudo.

\section{REFERENCIAL TEÓRICO}

\subsection{Processo de Convergência das Normas Contábeis}

A convergência das normas contábeis ao padrão internacional não ocorreu de forma instantânea. Esse processo tem se revelado uma busca incessante, a que, há anos, diversos organismos nacionais e internacionais vêm dedicando tempo e esforço. A convergência das normas contábeis é o processo por meio do qual vários países realizam mudanças em suas normas contábeis, uniformizando-as e respeitando as peculiaridades e características de cada região (SILVA; MADEIRA; ASSIS, 2004).

De acordo com Bradshaw e Miller (2007), há evidências de que a adoção internacional de um conjunto único de normas contábeis tem o potencial de aumentar a comparabilidade das informações contábeis entre os países que diferem econômica, política e culturalmente.

Esse processo de convergência das normas contábeis deve-se ao crescente desenvolvimento tecnológico e do comércio internacional, por meio do qual se estabeleceu uma maior interdependência das nações, evidenciando o fenômeno da globalização. A convergência dos padrões contábeis internacionais facilita a comunicação e contribui para suprimir as diferenças internacionais nos relatórios financeiros (NIYAMA, 2005).

Bradshaw e Miller (2007) entendem que esse movimento de harmonização das normas contábeis em âmbito mundial parece irreversível, havendo, no entanto, poucas evidências de que resultará em real harmonização das práticas contábeis. Ainda de acordo com Bradshaw e Miller (2007), a convergência das normas contábeis provavelmente terá impacto significativo no aumento global da comparabilidade das informações contábeis.

Com relação aos estudos sobre a convergência das práticas contábeis ao padrão internacional, ressalta-se que o tema já vem sendo pesquisado e debatido em todo o mundo. Barker e Barbu (2007) verificaram que, de um total de 212 artigos em inglês publicados no período de 1965 a 2004, foram veiculados 21 nos primeiros anos, 46 nos anos intermediários e 135 nos anos finais. Como se percebe, a convergência aos padrões contábeis internacionais já é uma realidade em âmbito mundial. "A comunidade europeia estabeleceu o ano de 2005 para adoção integral pela primeira vez das IFRS. A adesão dos países europeus às IFRS foi rápida" (ERNST \& YOUNG; FIPECAFI, 2009, p. xxi).

Segundo dados do IASB (2009), mais de cem países já exigem ou permitem o uso de IFRS em suas práticas contábeis ou são convergentes com as normas do órgão. Austrália, Canadá, China, Hong Kong, Noruega, Suécia, Brasil e Colômbia são alguns dos últimos países a integrar essa lista (ERNST \& YOUNG; FIPECAFI, 2009, p. xxi).

Em âmbito mundial, o IASB é o organismo responsável pela emissão das IFRS, dedicando-se ao estudo e à elaboração de padrões contábeis internacionais. Sediado em Londres, o IASB foi criado em 2001 para desenvolver um conjunto único de normas contábeis internacionais, capaz de proporcionar mais qualidade, transparência e comparabilidade às informações contábeis e de promover a convergência das normas contábeis aos padrões internacionais de contabilidade, com alta qualidade.

Segundo Niyama (2005), um dos principais benefícios esperados pelo IASB consiste em viabilizar a comparabilidade das informações contábeis empresariais em diferentes países, possibilitando a compreensão e a interpretação dos dados gerados pelas entidades de diferentes economias e tradições.

Além do IASB, outros organismos também atuam no processo de convergência das práticas contábeis, como The International Federation of Accoutants (IFAC), The 
International Organization of Securities Commission (IOSCO), Organization for Economic Cooperation and Development (OECD), The European Union (EU), The Confederation of Asian and Pacific Accountants (CAPA) e Federation des Experts Comptables Européens (FEE).

O processo de convergência das normas contábeis brasileiras aos padrões internacionais ocorre em ritmo acelerado. Braga e Almeida (2008) informam que esse processo teve início em novembro de 1990, com a elaboração de um Anteprojeto de reformulação da Lei $\mathrm{n}^{\circ}$. 6.404/76, relativamente às normas contábeis. O Anteprojeto foi encaminhado ao Poder Executivo em 1999, e teve como objetivo adequar a Lei das Sociedades Anônimas para atendimento das necessidades de transparência e qualidade das informações contábeis, além de criar condições para a convergência da contabilidade brasileira às melhores práticas contábeis internacionais.

No ano 2000, verificou-se a integração do Anteprojeto, relativamente às reformas contábeis, ao Projeto de Lei (PL) $\mathrm{n}^{\circ}$. 3.741. O PL versava sobre a modernização das disposições da Lei $\mathrm{n}^{\circ}$. 6.404/76 e sua harmonização com os princípios fundamentais e as melhores práticas contábeis internacionais (BRASIL, 2000). O PL tinha como principal finalidade eliminar as barreiras regulatórias que impediam a inserção total das companhias abertas no processo de convergência contábil internacional e elevar o grau de transparência das demonstrações contábeis, incluindo as sociedades de grande porte, além das sociedades por ações (BRAGA; ALMEIDA, 2008).

Em 2005, o Instituto dos Auditores Independentes do Brasil (IBRACON, 2005) publicou a Norma de Procedimento Contábil (NPC) $n^{\circ}$. 27, alinhando as práticas contábeis adotadas no Brasil e as práticas amparadas na legislação societária ao avanço na convergência com as normas contábeis internacionais. Naquele mesmo ano, o Conselho Federal de Contabilidade (CFC, 2005) publicou a Resolução $\mathrm{n}^{\circ}$. 1.055/2005, que criava o CPC, no modelo do IASB.

Em 2007, a CVM publicou a Instrução $n^{\circ}$. 457, estabelecendo que as companhias abertas devem apresentar suas demonstrações financeiras consolidadas de acordo com o padrão contábil internacional, seguindo os pronunciamentos do IASB (CVM, 2007). No mesmo ano, o CFC (2007) publicou a Resolução $n^{\circ}$. 1.103, criando o Comitê Gestor da Convergência no Brasil, para o acompanhamento dos pronunciamentos do $\mathrm{CPC}$, com o objetivo de alinhar as ações do processo de convergência às necessidades do país.

O ápice desse processo, no Brasil, foi alcançado após o advento da Lei $\mathrm{n}^{\circ}$. 11.638/07, incluindo o seguinte dispositivo no $\S 5^{\circ}$ do art. 177 da Lei $\mathrm{n}^{\circ}$. 6.404/76: "As normas expedidas pela Comissão de Valores Mobiliários [...] deverão ser elaboradas em consonância com os padrões internacionais de contabilidade adotados nos principais mercados de valores mobiliários" (BRASIL, 2007). A Lei $\mathrm{n}^{\circ}$. 11.941, de 2009, também introduziu modificações na Lei $\mathrm{n}^{\circ}$. 6.404/76, estabelecendo práticas contábeis, convergindo para as normas internacionais de contabilidade (Internacional Financial Reporting Standards - IFRS).

Já na vigência da nova legislação societária brasileira, o CPC publicou o Pronunciamento $n^{\circ}$. 13, que trata da adoção inicial da Lei $n^{\circ}$. 11.638/07 e da MP $n^{\circ}$. 449/08 (convertida na Lei $\mathrm{n}^{\circ}$. 11.941/09). Os órgãos reguladores aprovaram o CPC 13, transformando-o em norma, tornando, assim, obrigatória sua adoção pelas empresas. A CVM (2008b) divulgou sua Deliberação $\mathrm{n}^{\circ}$. 565/08. O CFC (2009) publicou a Resolução $\mathrm{n}^{\circ}$. 1.152/09. O Ibracon (2009) aprovou o Comunicado Técnico $\mathrm{n}^{\circ}$. 01/09; todos eles fazendo menção específica à adoção inicial da Lei n ${ }^{\circ}$. 11.638/07 e da Lei n ${ }^{\circ} .11 .941 / 09$.

\subsection{Ajuste a Valor Presente (AVP)}

A mensuração dos elementos patrimoniais a valor presente foi introduzida na contabilidade brasileira pela Instrução $n^{\circ}$. 191/92 da CVM, que definia procedimentos que 
deveriam ser observados pelas companhias abertas, na elaboração de demonstrações contábeis pela Correção Monetária. Em 31 de dezembro de 1995, tais procedimentos foram abolidos, em função da edição da Lei $\mathrm{n}^{\circ}$ 9249/95, que extinguiu a correção monetária nas demonstrações contábeis. As Leis $\mathrm{n}^{\circ}$. 11.638/07 e $\mathrm{n}^{\circ}$. 11.941/09 determinaram que tal procedimento fosse novamente adotado, tendo-se registrado impactos relevantes nos resultados das empresas no ano de 2008 (SANTOS; CALIXTO, 2009).

Moribe, Panosso e Marroni (2007, p. 27) pesquisaram sobre o Ajuste a Valor Presente em conformidade com as IFRS, observando, no âmbito das empresas, a necessidade de destacar a correção monetária e o AVP das contas com valor monetário futuro, como Fornecedores e Clientes, e assim se manifestaram com relação ao AVP:

Devido às elevadas taxas de juros prefixadas praticadas no Brasil, impelindo um custo financeiro oneroso, aplicou-se, no caso prático, o Ajuste a Valor Presente para evidenciar as receitas e despesas financeiras contidas nos valores realizáveis e exigíveis antes da conversão para moeda constante. Possibilitando, assim, apresentar um resultado mais próximo da realidade em cada período, bem como conhecer um valor livre de qualquer ônus financeiro para ser convertido em moeda constante.

O AVP constitui um marco importante para os critérios de mensuração dos elementos patrimoniais na contabilidade brasileira. Desloca a contabilidade de uma posição puramente objetiva, de divulgação do balanço a custo histórico, para uma posição de valor econômico, promovendo a divulgação de informações mais próximas da realidade econômica. Mediante utilização da técnica de ajuste a valor presente, as contas do Ativo e as do Passivo são avaliadas por critérios de mensuração que possibilitam apresentá-las a valores correspondentes às respectivas datas de transação (MORIBE; PANOSSO; MARRONI, 2007).

De acordo com Braga e Almeida (2008), devido à exigência do cálculo de AVP dos ativos e passivos, as Leis $\mathrm{n}^{\circ}$. 11.638/07 e $\mathrm{n}^{\circ}$. 11.941/09 procuram solucionar o problema referente aos juros embutidos nos preços das operações a prazo, visto que, geralmente, as entidades dispensavam às transações a prazo o mesmo tratamento contábil das transações à vista, ignorando a variação do valor do dinheiro no tempo e, portanto, apurando resultados distorcidos da realidade econômica.

\footnotetext{
Valor presente: os ativos são mantidos pelo valor presente, descontado, do fluxo futuro de entrada líquida de caixa que se espera seja gerado pelo item no curso normal das operações da entidade. Os passivos são mantidos pelo valor presente, descontado, do fluxo futuro de saída líquida de caixa que se espera seja necessário para liquidar o passivo no curso normal das operações da entidade (ERNST \& YOUNG; FIPECAFI, 2009, p. 8).
}

Nos EUA, o Financial Accounting Standards Board (FASB), organização privada americana, criada em 1973, designada na organização do setor privado, estabelece as normas de contabilidade financeira. As normas emitidas pelo FASB regem a elaboração das demonstrações financeiras das empresas que utilizam US GAAP (princípios contábeis geralmente aceitos nos EUA). Tem como missão estabelecer e melhorar os padrões de contabilidade e relatórios financeiros para a orientação e educação do público, compreendendo emitentes, auditores e usuários da informação financeira.

O FASB (2000) trata detalhadamente da mensuração a valor presente na Statement of Financial Accounting Concepts (SFAC) $\mathrm{n}^{\circ} .7$ - Using Cash Flow Information and Present Value in Accounting Measurements, segundo a qual o objetivo da mensuração a valor presente consiste em capturar, na medida do possível, a diferença econômica entre os conjuntos de futuros fluxos de caixa estimados da empresa. O FASB (2000) relaciona os seguintes componentes envolvidos na mensuração do AVP: uma estimativa do fluxo de caixa futuro, ou, em casos mais complexos, séries de fluxos de caixa futuros em épocas diferentes; expectativas sobre eventuais variações no valor ou no momento desses fluxos de caixa; o 
valor do dinheiro no tempo; o preço para suportar a incerteza inerente ao Ativo ou ao Passivo; outros componentes não claramente identificáveis, incluindo fatores de iliquidez e imperfeições do mercado. Ressalta-se que as declarações do FASB não estabelecem prescrições de práticas contábeis de divulgação.

O IASB ainda não emitiu pronunciamento específico sobre o Ajuste a Valor Presente, abordando o assunto de forma dispersa. O tema é tratado em diversas normas. Até maio de 2009, o IASB (2009) ainda articulava com o FASB a definição de um procedimento acerca do método de mensuração a valor presente, como pode ser visto no memorando: For Discussion at the May 5, 2009 IASB Education Session and the May 6, 2009 FASB Education Session.

Com relação ao AVP, a Lei $\mathrm{n}^{\circ}$. 11.638/07 incluiu o inciso VIII no art. 183 da Lei $\mathrm{n}^{\circ}$. 6.404/76, dispondo sobre os itens do Ativo: "os elementos do ativo decorrentes de operações de longo prazo serão ajustados a valor presente, sendo os demais ajustados quando houver efeito relevante" (BRASIL, 2007). Já a Lei $n^{\circ}$. 11.941/09 alterou o inciso III do art. 184 da mesma Lei $\mathrm{n}^{\circ}$. 6.404/76, dispondo sobre os itens do Passivo: "as obrigações, os encargos e os riscos classificados no passivo não circulante serão ajustados ao seu valor presente, sendo os demais ajustados quando houver efeito relevante" (BRASIL, 2009).

Embora o IASB ainda não haja emitido norma internacional específica sobre o AVP, o CPC, no sentido de garantir aplicabilidade para essa prática contábil durante o processo de convergência das normas contábeis brasileiras, elaborou o Pronunciamento Técnico $\mathrm{n}^{\circ} .12$, consolidando a posição do IASB contida em diversas IFRS. Para produzir esse documento, o CPC também se baseou nas declarações do FASB e na literatura pertinente.

O Pronunciamento Técnico CPC 12 trata especificamente da mensuração a valor presente e tem como objetivo básico estabelecer os requisitos a serem observados quando do AVP dos elementos do Ativo e do Passivo, tratando ainda da taxa de desconto apropriada a ser utilizada e dos cuidados necessários para se evitar vieses (CPC, 2008a). O teor do CPC 12 evidencia a preocupação em preservar características qualitativas da informação contábil, como por exemplo, relevância e confiabilidade. Preocupou-se também em esclarecer que trata essencialmente de questões de mensuração. A mensuração contábil a valor presente deve ser aplicada sempre no reconhecimento inicial dos ativos e passivos. Entretanto, o CPC 12 não enumerou os ativos ou passivos alcançados, estabelecendo apenas diretrizes gerais.

O CPC 13, referente à adoção inicial da Lei n. 11.638/07 e da MP n . 449/08 (Lei nº. 11.941/09), aborda o critério de mensuração dos itens patrimoniais. Orienta que os elementos do Ativo e do Passivo decorrentes de operações de longo prazo, ou mesmo de curto prazo, quando houver efeitos relevantes, devem ser ajustados a valor presente, tomando-se por base a data de origem da transação (CPC, 2008b). O CPC 13 estabelece ainda que se admite, para fins de apuração do saldo inicial na data de transição, que seja feito o cálculo do AVP para todos os saldos em aberto, com base em cálculo global, desde que os itens ou saldos de cada grupo de contas detenham características razoavelmente uniformes (CPC, 2008b).

O Ajuste a Valor Presente deve ser realizado com base em taxas de desconto que reflitam as melhores avaliações do mercado quanto ao valor do dinheiro no tempo e os riscos específicos do Ativo e do Passivo em suas datas originais, ou seja, na data de transação de cada evento (CPC, 2008a). O CPC 12 estabelece que a quantificação do AVP deve ser obtida em base exponencial pro rata die, a partir da data de origem de cada transação, sendo os seus efeitos apropriados nas contas a que se vinculam. As contrapartidas dessas operações de ajuste devem ser refletidas nas contas de receitas e despesas financeiras, para ativos e passivos, respectivamente. Porém, poderão ainda compor receitas e despesas operacionais, se a entidade justificar que realiza atividades de financiamento operacionalmente (CPC, 2008a).

O CPC 12 estabelece as informações mínimas a serem prestadas pelas empresas nas notas explicativas das demonstrações contábeis, quando da realização do ajuste a valor presente. Essas divulgações devem possibilitar que os usuários obtenham entendimento 
inequívoco das mensurações a valor presente levadas a efeito para ativos e passivos. São elas:

a) descrição pormenorizada do item objeto da mensuração a valor presente, natureza de seus fluxos de caixa (contratuais ou não) e, se aplicável, o seu valor de entrada cotado a mercado;

b) premissas utilizadas pela administração, taxas de juros decompostas por prêmios incorporados e por fatores de risco (risk-free, risco de crédito etc.), montantes dos fluxos de caixa estimados ou séries de montantes dos fluxos de caixa estimados, horizonte temporal estimado ou esperado, expectativas em termos de montante e temporalidade dos fluxos (probabilidades associadas);

c) modelos utilizados para cálculo de riscos e inputs dos modelos;

d) breve descrição do método de alocação dos descontos e do procedimento adotado para acomodar mudanças de premissas da administração;

e) propósito da mensuração a valor presente, se para reconhecimento inicial; ou

f) nova medição e motivação da administração para levar a efeito tal procedimento;

g) outras informações consideradas relevantes (CPC, 2008a, p. 10).

As exigências de divulgação do CPC 12 têm o objetivo de garantir a transparência aos usuários das demonstrações contábeis. Contudo, é possível que, mesmo havendo a exigência da divulgação das informações acerca dos ajustes a valor presente, algumas empresas não as tenham divulgado devido ao fato de ser recente a edição do CPC 12 e aos elevados custos associados a essa divulgação.

\section{METODOLOGIA}

Dado o objetivo proposto de investigar junto a empresas brasileiras o grau de atendimento das orientações referentes às práticas de divulgação da aplicação do Ajuste a Valor Presente dos itens patrimoniais, definidas no CPC 12, foram examinadas as Demonstrações Financeiras Padronizadas (DFP) do exercício findo em 31/12/2008, publicadas pelas empresas listadas na BM\&FBovespa e disponibilizadas em seu portal eletrônico até 30 de setembro de 2009. Trata-se, portanto, de pesquisa exploratória, adotandose procedimento documental.

A população desta pesquisa, que é o grupo de estudo considerado para os propósitos do trabalho (COLLIS; HUSSEY, 2005), compreende as 433 empresas listadas nos níveis diferenciados de governança corporativa 1 (N1), 2 (N2) e Novo Mercado (NM) e no mercado tradicional (MT) da BM\&FBovespa.

Foram excluídas do estudo 83 empresas do setor financeiro e afins, conforme classificação feita pela BM\&FBovespa, visto que o setor é regulado por normas específicas emitidas pelo Banco Central, apresentando particularidades em suas operações, o que dificultaria comparações com empresas de outros setores. Foram também eliminadas da pesquisa 16 outras empresas, cujas DFPs não foram localizadas no portal eletrônico da BM\&FBovespa. Assim, trabalhou-se com uma amostra de 334 companhias, conforme discriminado na Tabela 1.

Tabela 1 - População e Amostra da pesquisa

\begin{tabular}{l|c|c|c|c}
\hline \multicolumn{1}{c|}{ Segmento } & População & $\begin{array}{c}\mathbf{N}^{\mathbf{0}} \text { de empresas do } \\
\text { setor financeiro e } \\
\text { afins excluídas }\end{array}$ & $\begin{array}{c}\mathbf{N}^{\mathbf{0}} \text { de empresas } \\
\text { desconsideradas } \\
\text { por falta de dados }\end{array}$ & Amostra \\
\hline Mercado Tradicional & $\mathbf{2 7 5}$ & $\mathbf{6 0}$ & $\mathbf{1 6}$ & $\mathbf{1 9 9}$ \\
\hline Nível 1 & 38 & 11 & - & 27 \\
Nível 2 & 18 & 3 & - & 15 \\
Novo Mercado & 102 & 9 & - & 93 \\
\hline Níveis diferenciados & $\mathbf{1 5 8}$ & $\mathbf{2 3}$ & $\mathbf{1 6}$ & $\mathbf{1 3 5}$ \\
\hline Total & $\mathbf{4 3 3}$ & $\mathbf{8 3}$ & $\mathbf{1 6}$ \\
\hline
\end{tabular}

Fonte: Dados da pesquisa. 
Definida a amostra objeto do estudo, passou-se ao exame das notas explicativas (NE) das Demonstrações Financeiras Padronizadas das companhias. Inicialmente, realizou-se levantamento para identificação das empresas que mencionavam a aplicação do CPC 12 no exercício de 2008. Foram então relacionadas 186 empresas que comentavam em suas NEs a nova prática contábil introduzida pela Lei $\mathrm{n}^{\circ}$. 11.638/07. Dentre essas empresas, foram selecionadas as que haviam aplicado o teste e registrado seus impactos nas demonstrações contábeis, sendo identificado um total de 110 companhias. Para essas, foram levantadas as práticas de divulgação da aplicação do Ajuste a Valor Presente. Na coleta desses dados secundários, utilizou-se instrumento elaborado especificamente para os fins desta pesquisa.

A leitura das Notas Explicativas possibilitou identificar o grau de observância, pelas 110 empresas, de cada uma das cinco orientações definidas no CPC 12, aplicáveis para o ano de 2008, relacionadas no Quadro 1.

1) Descrever os itens objeto de mensuração a valor presente;
2) Evidenciar as taxas de juros utilizadas no cálculo de AVP;
3) Explicitar modelos utilizados para cálculo de riscos;
4) Realizar breve descrição do método de alocação dos descontos; e
5) Explicitar a motivação da administração para realizar o AVP.

Quadro 1 - Práticas de divulgação sobre o Ajuste a Valor Presente definidas no CPC 12. Fonte: adaptado do CPC 12 (CPC, 2008a).

Para cada uma dessas práticas de divulgação foi criada uma variável dicotômica que recebeu o valor 1, quando a empresa atendeu ao requisito, ou zero, quando a empresa não atendeu ao requisito. Assim, foi possível definir uma variável Pontuação pela Divulgação, que refletisse o grau de atendimento da empresa às práticas de divulgação definidas no CPC 12. Essa variável recebeu os atributos $0,1,2,3,4$ e 5 . O atributo 0 indica que a empresa não atendeu a nenhuma das divulgações investigadas, enquanto o valor 5 significava que a empresa atendeu a todas as práticas de divulgação estabelecidas no CPC 12.

Adicionalmente, foi consultado para cada empresa o segmento de listagem, concomitantemente à coleta dos dados, em data até 30/09/2009. Os dados obtidos foram organizados em planilha Excel, para posterior análise com auxílio do software SPSS Statistics Data Editor, versão 17.0.

Para o tratamento e análise dos dados, após sua tabulação, foram utilizadas medidas estatísticas de tendência central das observações e calculadas medidas de estatística descritiva, como média, mediana, moda, variância e desvio-padrão. Utilizou-se ainda a distribuição de frequência, que possibilitou conhecer o "meio" aproximado dos grupos de dados (COLLIS; HUSSEY, 2005). Essas medidas estatísticas possibilitaram uma análise geral do grau de atendimento das empresas às práticas de divulgação sobre o AVP, definidas no CPC 12.

Tomando por base a hipótese geral do estudo, assim como os resultados apresentados pela estatística descritiva, foram definidas as seguintes hipóteses para serem testadas:

a) As Pontuações pela Divulgação das empresas do Novo Mercado e do Nível 2 $\left(\mathrm{PD}_{\mathrm{NMN} 2}\right)$ são superiores as Pontuações pela Divulgação das empresas do mercado tradicional $\left(\mathrm{PD}_{\mathrm{MT}}\right)$ :

$$
\mathrm{H}_{1}: \mathrm{PD}_{\mathrm{NMN} 2} \leq \mathrm{PD}_{\mathrm{MT}}
$$

b) As Pontuações pela Divulgação das empresas do Novo Mercado ( $\mathrm{PD}_{\mathrm{NM}}$ ) são superiores as Pontuações pela Divulgação das empresas do mercado tradicional $\left(\mathrm{PD}_{\mathrm{MT}}\right)$ :

$$
\mathrm{H}_{2}: \mathrm{PD}_{\mathrm{NM}} \leq \mathrm{PD}_{\mathrm{MT}}
$$

Foram realizados testes de diferença entre médias, sendo aplicados testes nãoparamétricos, utilizando o modelo de Mann-Whitney. Não foram realizados testes 
paramétricos $t$ (Student), visto que a aplicação do teste Kolmogorov-Smirnov revelou que os dados das amostras não apresentavam distribuição normal.

\section{ANÁLISE DOS RESULTADOS}

Neste tópico apresentam-se as práticas de divulgação relativas ao AVP observadas pelas companhias abertas brasileiras quando da publicação de suas demonstrações contábeis relativas ao exercício de 2008. Também são apresentados os resultados dos testes estatísticos realizados com o objetivo de responder ao problema de pesquisa.

\subsection{Divulgação da Nova Prática Contábil de Ajuste a Valor Presente (AVP)}

Conforme comentado, do total de 334 empresas pesquisadas, apenas 186 mencionaram a nova prática contábil de AVP. Os dados da Tabela 2 revelam que as empresas do Nível 2 e do Novo Mercado foram aquelas que em maior proporção mencionaram a prática.

Tabela 2 - Comentário sobre o Ajuste a Valor Presente (AVP) em nota explicativa

\begin{tabular}{|c|c|c|c|c|c|c|}
\hline \multirow{2}{*}{\multicolumn{2}{|c|}{ Segmento }} & \multirow[b]{2}{*}{ MT } & \multicolumn{3}{|c|}{ Nível de GC } & \multirow[b]{2}{*}{ Total } \\
\hline & & & N1 & $\mathbf{N} 2$ & NM & \\
\hline \multirow{2}{*}{$\stackrel{\Xi}{\Xi}$} & Quant. & 98 & 12 & 10 & 66 & \multirow{2}{*}{186} \\
\hline & $\%$ & 49,25 & 44,44 & 66,67 & 70,97 & \\
\hline \multirow{2}{*}{$\stackrel{\text { I }}{\text { Z }}$} & Quant. & 101 & 15 & 5 & 27 & \multirow{2}{*}{148} \\
\hline & $\%$ & 50,75 & 55,56 & 33,33 & 29,03 & \\
\hline
\end{tabular}

Fonte: Dados da pesquisa.

Examinando-s as NEs dessas 186 empresas, foi possível verificar que 110 delas declararam haver registrado os impactos do Ajuste a Valor Presente. As demais, perfazendo 76 companhias, informaram não haver necessidade de aplicação do AVP, dadas as características de seus ativos e passivos; ou não contabilizaram os efeitos do AVP, considerados não relevantes (Tabela 3).

Tabela 3 - Aplicação do AVP e registro dos efeitos nas Demonstrações Contábeis

\begin{tabular}{|c|c|c|c|c|c|c|}
\hline \multirow{2}{*}{\multicolumn{2}{|c|}{ Segmento }} & \multirow{3}{*}{$\begin{array}{c}\text { MT } \\
48\end{array}$} & \multicolumn{3}{|c|}{ Nível de GC } & \multirow[b]{2}{*}{ Total } \\
\hline & & & N1 & N2 & NM & \\
\hline \multirow{2}{*}{ 的 } & Quant. & & 10 & 6 & 46 & \multirow{2}{*}{110} \\
\hline & $\%$ & 48,98 & 83,33 & 60,00 & 69,70 & \\
\hline \multirow{2}{*}{ 楉 } & Quant. & 50 & 2 & 4 & 20 & \multirow{2}{*}{76} \\
\hline & $\%$ & 25,13 & 7,41 & 26,67 & 21,51 & \\
\hline
\end{tabular}

Fonte: Dados da pesquisa.

De acordo com o CPC 13, no momento da adoção inicial da Lei ${ }^{\circ}$. 11.638/07, as entidades deveriam apresentar, em nota explicativa, um sumário das práticas contábeis modificadas, acompanhado dos seus efeitos no resultado de 2008. Esse procedimento deveria ser observado pelas 110 companhias mencionadas com relação ao AVP. Contudo, 37 delas não adotaram essa prática. Verificou-se, também, que dentre as 73 companhias que observaram a orientação do CPC 13, 49 registraram redução no resultado de 2008 em decorrência da realização do Ajuste a Valor Presente (Tabela 4).

Tabela 4 - Impactos no Resultado do Exercício de 2008

\begin{tabular}{|c|c|c|c|c|c|}
\hline \multirow[b]{2}{*}{ Segmentos BM\&FBovespa } & \multirow[b]{2}{*}{ MT } & \multicolumn{3}{|c|}{ Nível de GC } & \multirow[b]{2}{*}{ Total } \\
\hline & & N1 & N2 & NM & \\
\hline Efeito positivo & 14 & 2 & 1 & 7 & 24 \\
\hline Efeito Negativo & 18 & 6 & 2 & 23 & 49 \\
\hline Não Divulgou & 16 & 2 & 3 & 16 & 37 \\
\hline
\end{tabular}

Fonte: Dados da pesquisa. 


\subsection{Observância às Orientações do CPC 12}

Levando em conta que o AVP pode gerar impactos relevantes sobre os elementos patrimoniais, o CPC 12 define um conjunto de informações mínimas a serem apresentadas pelas empresas em suas notas explicativas (Quadro 1). O CPC 12 procura garantir a transparência das demonstrações contábeis, de modo a possibilitar que os usuários tenham entendimento inequívoco das mensurações a valor presente de ativos e passivos.

Investigou-se o grau de observância às orientações de divulgação do CPC 12 das 110 empresas que declararam em Nota Explicativa haver contabilizado os impactos do AVP nas Demonstrações Financeiras Padronizadas de 2008. Os dados levantados são apresentados na Tabela 5.

Tabela 5 - Observância às Práticas de Divulgação sobre o AVP definidas no CPC 12

\begin{tabular}{|c|c|c|c|c|}
\hline Prática & Sim & $\%$ & Não & $\%$ \\
\hline Descrever os itens objeto de mensuração a valor presente & 71 & $64,5 \%$ & 39 & $35,5 \%$ \\
\hline $\begin{array}{l}\text { Evidenciar as taxas de juros utilizadas no cálculo de ajuste a valor } \\
\text { presente }\end{array}$ & 23 & $20,9 \%$ & 87 & $79,1 \%$ \\
\hline Explicitar modelos utilizados para cálculo de riscos & 2 & $1,8 \%$ & 108 & $98,2 \%$ \\
\hline Realizar breve descrição do método de alocação dos descontos & 10 & $9,1 \%$ & 100 & $90,9 \%$ \\
\hline $\begin{array}{l}\text { Descrever a motivação da administração para levar a cabo tal } \\
\text { procedimento }\end{array}$ & 110 & $100,0 \%$ & 0 & $0,0 \%$ \\
\hline
\end{tabular}

Fonte: Dados da pesquisa.

No geral, observou-se um insatisfatório grau de observância das determinações do CPC 12 pelas companhias abertas, no período da adoção inicial das Leis $\mathrm{n}^{\circ}$. 11.638/07 e $\mathrm{n}^{\circ}$. 11.941/09. Verificou-se que, via de regra, as empresas limitaram-se a descrever os itens objeto de mensuração a valor presente $(64,5 \%)$ e a apresentar a motivação da administração para levar a cabo tal procedimento (100\%). Os demais itens foram quase totalmente negligenciados pelas empresas. Vale destacar que apenas duas empresas detalharam os modelos utilizados para cálculo de riscos, ou seja, 99\% das empresas não observaram essa orientação do CPC. É de se supor que tenha sido comprometido o entendimento dos usuários externos acerca dos impactos do Ajuste a Valor Presente nos resultados das companhias.

Tabela 6 - Grau de observância às Práticas de Divulgação definidas no CPC 12 por segmento da BM\&FBovespa

\begin{tabular}{l|c|c|c|c|c|c|c|c}
\multicolumn{1}{c|}{ Prática } & \multicolumn{2}{|c|}{ MT (48) } & \multicolumn{2}{c|}{ N1 (10) } & \multicolumn{2}{c|}{ N2 (6) } & \multicolumn{2}{c}{ NM (46) } \\
\cline { 2 - 9 } & Quant & \% & Quant & \% & Quant & \% & Quant & \% \\
\hline $\begin{array}{l}\text { Descrever os itens objeto de mensuração a } \\
\text { valor presente }\end{array}$ & 28 & 58,3 & 6 & 60,0 & 5 & 83,3 & 32 & 69,6 \\
\hline $\begin{array}{l}\text { Evidenciar as taxas de desconto utilizadas } \\
\text { no cálculo de ADP }\end{array}$ & 9 & 18,8 & 0 & 0,0 & 1 & 16,7 & 13 & 28,3 \\
\hline $\begin{array}{l}\text { Explicitar modelos utilizados para cálculo } \\
\text { de riscos }\end{array}$ & 1 & 2,1 & 0 & 0,0 & 0 & 0,0 & 1 & 2,2 \\
\hline $\begin{array}{l}\text { Realizar breve descrição do método de } \\
\text { alocação dos descontos }\end{array}$ & 3 & 6,3 & 1 & 10,0 & 0 & 0,0 & 6 & 13,0 \\
\hline $\begin{array}{l}\text { Descrever a motivação da administração } \\
\text { para levar a cabo tal procedimento }\end{array}$ & 48 & 100,0 & 10 & 100,0 & 6 & 100,0 & 46 & 100,0 \\
\hline
\end{tabular}

Fonte: Dados da pesquisa.

Analisando-se o grau de observância por segmento de listagem da BM\&FBovespa, foi possível constatar que as empresas do Novo Mercado tiveram maior observância das orientações do CPC 12 (Tabela 6). A não-observância foi mais frequente entre as empresas do Nível 1 e do mercado tradicional, que revelaram comportamentos similares. Por seu turno, $83,3 \%$ e $69,6 \%$ das empresas do Nível 2 e do Novo Mercado, respectivamente, descreveram 
os elementos objeto de AVP, enquanto as empresas do mercado tradicional e do Nível 1 registraram percentuais de $58,3 \%$ e $60 \%$, respectivamente. A evidenciação da taxa de desconto adotada nos cálculos de AVP foi observada por $16,7 \%$ e $28,3 \%$ das empresas do Nível 2 e do Novo Mercado, respectivamente, e por 18,8\% das empresas do mercado tradicional. Nenhuma das 10 companhias do Nível 1 investigadas observou essa prática.

Assim, corrobora-se os achados de Santos e Calixto (2009) que verificaram uma diversidade de comportamento entre as empresas no momento da adoção inicial das novas práticas contábeis introduzidas pela Lei 11.638/07.

Não resta dúvida, como afirmam Braga e Almeida (2008), que a exigência do Ajuste a Valor Presente de ativos e passivos procura solucionar o problema referente aos juros embutidos nos preços das operações a prazo. Contudo, dado os resultados encontrados, ainda é preciso um esforço adicional dos órgãos reguladores no sentido de que tais procedimentos possam ser corretamente interpretados pelos usuários das demonstrações contábeis, já que podem alterar de forma relevante os resultados das companhias.

Conforme explicitado no tópico Metodologia, foi definida a variável Pontuação pela Divulgação, a qual procurou sintetizar o grau de observância das orientações de divulgação relativas ao AVP por parte das companhias. Cada empresa recebeu um escore, que variou de 1 a 5 pontos, em função dos itens de evidenciação publicados. Os escores das empresas da amostra são sumarizados na Tabela 7.

Tabela 7 - Pontuação pela Divulgação por segmento da BM\&FBovespa

\begin{tabular}{|c|c|c|c|c|c|c|c|}
\hline \multirow[b]{2}{*}{ Segmento } & \multicolumn{6}{|c|}{ Pontuação } & \multirow[b]{2}{*}{ Total } \\
\hline & 0 & 1 & 2 & 3 & 4 & 5 & \\
\hline MT & 0 & 19 & 20 & 6 & 3 & 0 & 48 \\
\hline N1 & 0 & 3 & 7 & 0 & 0 & 0 & 10 \\
\hline $\mathrm{N} 2$ & 0 & 0 & 6 & 0 & 0 & 0 & 6 \\
\hline $\mathrm{NM}$ & 0 & 14 & 18 & 7 & 7 & 0 & 46 \\
\hline Total & 0 & 36 & 51 & 13 & 10 & 0 & 110 \\
\hline
\end{tabular}

Fonte: Dados da pesquisa.

Chamou a atenção o número de empresas que se limitaram a apresentar a motivação da administração para realizar o AVP, totalizando 77, que são as empresas que assinalaram escore 1 na Pontuação pela Divulgação. É grave que, dentre essas, incluam-se 14 do NM, segmento que deveria adotar as melhores práticas de governança corporativa, primando pela transparência e prestação de contas. Observa-se também que a grande maioria das empresas (87\%) apresentou no máximo dois itens de evidenciação. Nenhuma das 110 empresas investigadas observou todas as cinco práticas mínimas de divulgação relativas ao AVP.

$\mathrm{Na}$ tentativa de investigar se ocorria um comportamento diferenciado das empresas, relacionado com o segmento de listagem, elaborou-se a Tabela 8, que apresenta a frequência acumulada das pontuações por segmento.

Tabela 8 - Pontuação pela Divulgação acumulada por segmento da BM\&FBovespa

\begin{tabular}{c|c|c|c|c|c|c|c|c}
\hline \multirow{2}{*}{ Pontuação } & \multicolumn{2}{|c|}{ Mercado Tradicional } & \multicolumn{2}{c|}{ Nível 1 } & \multicolumn{2}{c|}{ Nível 2 } & \multicolumn{2}{c}{ Novo Mercado } \\
\cline { 2 - 10 } & Quant. & $\begin{array}{c}\text { \% } \\
\text { Cumulativo }\end{array}$ & Quant. & $\begin{array}{c}\text { \% } \\
\text { Cumulativo }\end{array}$ & Quant. & $\begin{array}{c}\text { \% } \\
\text { Cumulativo }\end{array}$ & Quant. & $\begin{array}{c}\text { \% } \\
\text { Cumulativo }\end{array}$ \\
\hline 0 & 0 & 0,0 & 0 & 0,0 & 0 & 0,0 & 0 & 0,0 \\
\hline 1 & 19 & 39,6 & 3 & 30,0 & 0 & 0,0 & 14 & 30,4 \\
\hline 2 & 20 & 81,3 & 7 & 100,0 & 6 & 100,0 & 18 & 69,6 \\
\hline 3 & 6 & 93,8 & 0 & & 0 & & 7 & 84,8 \\
\hline 4 & 3 & 100,0 & 0 & & 0 & & 7 & 100,0 \\
\hline 5 & 0 & & 0 & & 0 & & 0 & \\
\hline
\end{tabular}

Fonte: Dados da pesquisa. 
A variável Pontuação pela Divulgação das empresas alcançou médias muito baixas, mesmo as do Novo Mercado (Tabela 9), que apresentaram média de 2,15. Vale destacar que as empresas do Nível 1 registraram a média mais baixa $(1,7)$, seguida pelas do mercado tradicional $(1,85)$ e do Nível $2(2,0)$.

Tabela 9 - Estatística descritiva da Pontuação pela Divulgação por segmento da BM\&FBovespa

\begin{tabular}{c|c|c|c|c|c|c}
\hline \multirow{2}{*}{ Segmento } & \multicolumn{7}{|c}{ Estatística descritiva } & Máximo \\
\cline { 2 - 7 } & Média & Mediana & Moda & Desvio-padrão & Mínimo & 1 \\
\hline MT & 1,8542 & 2 & 2 & 0,8749 & 1 & 2 \\
\hline N1 & 1,7000 & 2 & 2 & 0,4830 & 2 & 2 \\
\hline N2 & 2,0000 & 2 & 2 & 0,0000 & 1 & 4 \\
\hline NM & 2,1522 & 2 & 2 & 1,0321 & 1 & 4 \\
\hline
\end{tabular}

Fonte: Dados da pesquisa.

Com o propósito de avaliar a significância das variações observadas entre as médias da variável Pontuação pela Divulgação, realizou-se, inicialmente, teste não-paramétrico utilizando o modelo de Mann-Whitney, comparando os escores das empresas do Nível 2 e do Novo Mercado com os das companhias do mercado tradicional. Não foi utilizado o teste $t$ (Student) porque a aplicação do teste Kolmogorov-Smirnov revelou que os dados das amostras não apresentavam distribuição normal.

Conforme Tabela 10, o teste revelou que as médias dos grupos não são significativamente diferentes, ao nível de 5\%, não se confirmando a hipótese de que as Pontuações pela Divulgação das empresas do Novo Mercado e do Nível 2 são superiores as Pontuações pela Divulgação das empresas do mercado tradicional $\left(\mathrm{H}_{1}\right)$.

Em seguida, investigou-se a significância das variações entre os escores, confrontando-se apenas as empresas do mercado tradicional com as do Novo Mercado. Mais uma vez realizou-se o teste de Mann-Whitney, verificando-se mais uma vez que as médias dos grupos também não são significativamente diferentes, não se confirmando a hipótese de que as Pontuações pela Divulgação das empresas do Novo Mercado são superiores as Pontuações pela Divulgação das empresas do mercado tradicional $\left(\mathrm{H}_{2}\right)$.

Tabela 10 - Resultados dos testes de Mann-Whitney de diferenças entre médias

\begin{tabular}{c|c|c}
\hline Teste & NMN2 x MT & NM x MT \\
\hline Mann-Whitney U & 1074,50 & 933,50 \\
\hline Z & $-1,478$ & $-1,1369$ \\
\hline Significância & 0,142 & 0,172 \\
\hline
\end{tabular}

Fonte: Dados da pesquisa.

Os resultados da pesquisa indicam que a transparência foi negligenciada nas demonstrações contábeis de 2008, até mesmo pelas empresas do Novo Mercado da BM\&FBovespa.

\section{CONCLUSÕES}

O trabalho investigou o grau de observância das práticas de divulgação definidas no CPC 12, relativas ao Ajuste a Valor Presente, quando da adoção inicial das Leis $n^{\circ}$. 11.638/07 e $\mathrm{n}^{\circ}$. 11.941/09, examinando se houve maior observância pelas empresas dos níveis diferenciados de governança corporativa.

A população da pesquisa compreendeu as 433 empresas listadas nos níveis diferenciados de governança corporativa e no mercado tradicional da BM\&FBovespa. Foram excluídas do estudo 83 empresas do setor financeiro e afins e outras 16 cujas demonstrações contábeis não foram localizadas no portal eletrônico da BM\&FBovespa. Assim, trabalhou-se com uma amostra de 334 companhias. Dentre essas, verificou-se que apenas 110 tinham 
aplicado o Ajuste a Valor Presente e registrado seus impactos nas demonstrações contábeis de 2008, sendo para essas analisadas as práticas de divulgação relativas ao CPC 12.

Corroborando o estudo de Santos e Calixto (2009), foi observada uma diversidade de comportamentos entre as empresas no momento da adoção inicial das novas práticas contábeis introduzidas pela Lei $\mathrm{n}^{\circ}$. 11.638/07.

Verificou-se que, nas companhias abertas, houve um baixo grau de observância das práticas de divulgação definidas no CPC 12. Diferentemente do esperado, não se observou um maior atendimento às orientações de divulgação relativas ao Ajuste a Valor Presente por parte das empresas dos níveis diferenciados de governança corporativa. Para alguns itens de evidenciação, o estudo apontou que as empresas dos Nível 2 e Novo Mercado tiveram uma maior adesão às práticas de divulgação relativas ao Ajuste a Valor Presente, mas não foi possível comprovar, estatisticamente, a existência de um maior grau de observância, quando comparadas com as companhias do mercado tradicional.

Assim, as hipóteses do estudo foram rejeitadas, não tendo sido possível corroborar pesquisas anteriores que sinalizam a existência de relação positiva entre boas práticas de governança e comprometimento com a transparência, em geral, presente nas empresas dos níveis diferenciados de governança corporativa. Os resultados reforçam os achados de Santos e Calixto (2009), demonstrando que a transparência foi negligenciada nas demonstrações contábeis de 2008, até mesmo pelas empresas do Novo Mercado da BM\&FBovespa.

Dessa forma, sugere-se um esforço adicional dos órgãos reguladores e do Comitê de Pronunciamentos Contábeis no sentido de alertar as empresas sobre a necessidade de observância às práticas de divulgação, que são indispensáveis ao adequado entendimento das demonstrações contábeis.

\section{REFERÊNCIAS}

BARKER, C. R.; BARBU, E. M. Trends in research on international accounting harmonization ${ }^{\circ}$. The International Journal of Accounting, Illinois, Elsevier, v. 42, n. 3, p. 272-304, 2007. Disponível em: <http://www.sciencedirect.com/science/article/B6W4P4PB166B-1/2/57742c6b74b8ef1ff472505097ec9c50>. Acesso em: 21 jul. 2009. http://dx.doi.org/10.1016/j.intacc.2007.06.003

BOTOSAN, C. A. Disclosure level and the cost of equity capital. The Accounting Review, v. 72, n. 3, p. 323-349, 1997.

BRADSHAW, M. T.; MILLER, G. S. Will harmonizing accounting standards really harmonize accounting? Evidence from non - U.S. firms adopting US GAAP. In: Journal of Accounting, Auditing and Finance \& KPMG Foundation Conference on Transparency of Corporate Information, 2007, New York. Anais eletrônicos... New York: NYU, 2007. Disponível em: <http://w4.stern ${ }^{\circ}$.nyu.edu/emplibrary/BradshawMiller_JAAF_conference _version.pdf >. Acesso em: 9 jul. 2009.

BRAGA, H. R.; ALMEIDA, M. C. Mudanças contábeis na Lei Societária: Lei $\mathrm{n}^{\circ}$. 11.638, de 28-12-2007. São Paulo: Atlas, 2008.

BRASIL. Lei $\mathbf{n}^{\circ}$. 11.638, de 28 de dezembro de 2007. Altera e revoga dispositivos da Lei $\mathrm{n}^{\circ}$. 6.404, de 15 de dezembro de 1976, e da Lei n ${ }^{\circ}$. 6.385, de 7 de dezembro de 1976, e estende às sociedades de grande porte disposições relativas à elaboração e divulgação de demonstrações financeiras. Diário Oficial da República Federativa do Brasil, Brasília, 28 dez. 2007.

BRASIL. Lei $\mathbf{n}^{\circ}$. 11.941, de 27 de maio de 2009. Altera a legislação tributária federal relativa ao parcelamento ordinário de débitos tributários; concede remissão nos casos em que especifica; institui regime tributário de transição, e dá outras providências. Diário Oficial da República Federativa do Brasil, Brasília, 28 mai. 2009. 
BRASIL. Projeto de Lei $\mathbf{n}^{\circ}$. 3.741, de 8 de novembro de 2000. Altera e revoga dispositivos da Lei ${ }^{\circ}$. 6.404, de 15 de dezembro de 1976, define e estende às sociedades de grande porte disposições relativas à elaboração e publicação de demonstrações contábeis e dispõe sobre os requisitos de qualificação de entidades de estudo e divulgação de princípios, normas e padrões de contabilidade e auditoria como Organizações da Sociedade Civil de Interesse Público. Brasília, 8 nov.2000.

CONSELHO FEDERAL DE CONTABILIDADE (CFC). Resolução CFC $\mathbf{n}^{\circ} \mathbf{~ 1 . 0 5 5}$, de 24 de outubro de 2005. Cria o Comitê de Pronunciamentos Contábeis (CPC) e dá outras providências. Diário Oficial da República Federativa do Brasil, Brasília, 24 out. 2005.

CONSELHO FEDERAL DE CONTABILIDADE (CFC). Resolução CFC n . 1.103, de 28 de setembro de 2007. Cria o Comitê Gestor da Convergência no Brasil, e dá outras providências. Diário Oficial da República Federativa do Brasil, Brasília, 5 out. 2007.

CONSELHO FEDERAL DE CONTABILIDADE (CFC). Resolução CFC n . 1.152, de 23 de janeiro de 2009. NBCT 19.18 - Adoção Inicial da Lei $\mathrm{n}^{\circ}$. 11.638/07 e da MP n ${ }^{\circ}$ 449/08. Diário Oficial da República Federativa do Brasil, Brasília, 27 jan ${ }^{\circ} 2009$.

COLLIS, J.; HUSSEY, R. Pesquisa em administração: um guia prático para alunos de graduação e pós-graduação. 2. ed. Porto Alegre: Bookman, 2005.

COMITÊ DE PRONUNCIAMENTOS CONTÁBEIS (CPC). Pronunciamento Técnico CPC $\mathbf{n}^{\circ}$. 12, de 5 de dezembro de 2008. Ajuste a valor presente. Brasília: CPC, 5 dez. 2008a.

COMITÊ DE PRONUNCIAMENTOS CONTÁBEIS (CPC). Pronunciamento Técnico CPC $\mathbf{n}^{\circ}$. 13, de 5 de dezembro de 2008. Adoção inicial da Lei $\mathrm{n}^{\circ}$. 11.638/07 e da Medida Provisória $\mathrm{n}^{\circ}$. 449/08. Brasília: CPC, 5 dez. 2008b.

COMISSÃO DE VALORES MOBILIÁRIOS (CVM). Instrução CVM nº 457, de 13 de julho de 2007. Dispõe sobre a elaboração e divulgação das demonstrações financeiras consolidadas, com base no padrão contábil internacional emitido pelo International Accounting Standards Board (IASB). Diário Oficial da República Federativa do Brasil, Brasília, 16 jul. 2007.

COMISSÃO DE VALORES MOBILIÁRIOS (CVM). Deliberação CVM n . 564, de 17 de dezembro de 2008. Aprova o pronunciamento técnico CPC 12 do Comitê de Pronunciamentos Contábeis que trata do ajuste a valor presente. Diário Oficial da República Federativa do Brasil, Brasília, 22 dez. 2008a.

COMISSÃO DE VALORES MOBILIÁRIOS (CVM). Deliberação CVM n $\mathbf{n}^{\circ} \mathbf{5 6 5}$, de 17 de dezembro de 2008. Aprova o pronunciamento técnico CPC 13 emitido pelo Comitê de Pronunciamentos Contábeis, que trata da adoção inicial da Lei $n^{\circ}$. 11.638/07. Diário Oficial da República Federativa do Brasil, Brasília, 22 dez. 2008b.

ERNST \& YOUNG; FIPECAFI. Manual de normas internacionais de contabilidade: IFRS versus normas brasileiras. 1. ed. São Paulo: Atlas, 2009.

FINANCIAL ACCOUNTING STANDARDS BOARD (FASB). Statement of Financial Accounting Concepts $\mathbf{n}^{\circ}$. 7: using cash flow information and present value in accounting measurements. Norwalk, EUA, fev. 2000. Disponível em: <http://translate.google.com.br/translate?hl=pt-BR\&sl=en\&u=http://www.fasb.org/\&ei=jj1b Svv4I5OKNNfNOUI\&sa $=$ X\&oi=translate $\&$ resnum $=5 \& \mathrm{ct}=$ result $\&$ prev $=/$ search $\% 3 \mathrm{Fq} \% 3 \mathrm{Dfas}$ b\%26hl\%3Dpt-BR>. Acesso em: 13 jul. 2009.

FORKER, J. J. Corporate governance and disclosure quality. Accounting and Business Research, v. 22, n. 86, p. 111-124, 1992. 
GIROTTO, M. A migração das normas contábeis brasileiras para o padrão internacional: especialistas analisam o processo. Revista Brasileira de Contabilidade, Brasília, n. 175, p. 7, jan./fev., 2009.

INTERNATIONAL ACCOUNTING STANDARDS BOARD (IASB). For discussion at the May 5, 2009 IASB Education Session and the May 6, 2009 FASB Education Session. Londres, maio 2009. Disponível em: <http://www.iasb.org/NR/rdonlyres/A4F10A36-D7984597-B287-C14FA6C3392D/0/CurrentValueMeasurementMethodobs.pdf>. Acesso em: 13 jul. 2009.

INTERNATIONAL ACCOUNTING STANDARDS BOARD (IASB). IFRS around the world.

Disponível

em:

<http://www.iasb.org/About+Us/About+the+IASB/IFRSs+around+the+world.htm>. Acesso em: 15 jul. 2009.

INSTITUTO DOS AUDITORES INDEPENDENTES DO BRASIL (IBRACON). Norma de procedimentos contábeis $\mathbf{n}^{\mathbf{0}} \mathbf{2 7}$, de 29 de dezembro de 2005. Demonstrações Contábeis Apresentação e Divulgações. São Paulo: Ibracon, 2005.

INSTITUTO DOS AUDITORES INDEPENDENTES DO BRASIL (IBRACON). Comunicado Técnico no 01, de 19 de janeiro de 2009. Emissão de Parecer dos Auditores Independentes sobre o exame das primeiras demonstrações contábeis elaboradas de acordo com as novas práticas contábeis adotadas no Brasil trazidas pela Lei $\mathrm{n}^{\circ}$. 11.638/07, Medida Provisória 449/08 e pelos Pronunciamentos contábeis editados pelo CPC. São Paulo: Ibracon, 2009.

MORIBE, A. M.; PANOSSO, A.; MARRONI, C.H. Um enfoque sobre correção monetária integral e ajuste a valor presente em conformidade com as normas internacionais de contabilidade. Enfoque: Reflexão Contábil, Maringá, v. 26, n. 1, p. 17-28, jan./abr. 2007. Disponível em: <http://periodicos.uem.br/ojs/index.php/Enfoque/article/view/3577/4342>. Acesso em: 10 jul. 2009.

NIYAMA, J. K. Contabilidade internacional. São Paulo: Atlas, 2005.

SANTOS, E. S.; CALIXTO, L. Impactos do início da harmonização contábil internacional (Lei $n^{\circ}$. 11.638/08) nos resultados de 2008 das empresas brasileiras abertas. In: CONGRESSO BRASILEIRO DE CUSTOS, 16., 2009, Fortaleza. Anais... Fortaleza: ABC, 2009.

SILVA, C. B. A.; MADEIRA, G. J.; ASSIS, J. L. F. Harmonização de normas contábeis: um estudo sobre as divergências entre normas contábeis internacionais e seus reflexos na contabilidade brasileira. Revista Contemporânea de Contabilidade, Florianópolis, v. 1, n. 1, p. 115-139, jan./jun. 2004. 